\title{
Algumas Reflexões Sobre o CONTROLE JUdicial dA ADMINISTRAÇÃo PÚBlicA CONTEMPORÂNEA
}

DANIEL MITIDIERI FERNANDES DE OLIVEIRA ${ }^{\dagger}$

\section{UM DOSSIÊ SOBRE ESTADO ADMINISTRATIVO}

\begin{abstract}
RESUMO: O controle judicial da administração pública é um tema sobre o qual a doutrina apresenta dois específicos recortes. O primeiro deles é de matriz conceitual. O segundo é de matriz institucional. No primeiro recorte, a doutrina costuma dividir alguns fenômenos em atos administrativos vinculados e atos administrativos discricionários. Os atos vinculados correspondem a uma mera operação de aplicação da lei diante da situação concreta. Já os atos discricionários apresentariam margem de liberdade decisória maior para o gestor público tomador da decisão. Nesse sentido, só poderia haver substituição/ anulação do ato discricionário pelo judiciário em casos de razoável violação de bens e direitos socialmente relevantes, enquanto nos atos vinculados o controle é total. Ocorre que a inconsistência do significado de falta de razoabilidade de um ato para justificar um controle responsável sobre a administração abre espaço para reflexões institucionais. O objetivo do presente trabalho é repassar esses dois recortes, sugerindo, em seguida, um enfoque de segunda ordem para o problema da legitimidade do controle judicial dos atos administrativos. O referencial teórico para o

\footnotetext{
† Mestrando em teorias jurídicas contemporâneas pelo Programa de Pós-Graduação em Direito (PPGD) da Universidade Federal do Rio de Janeiro (UFRJ), Pesquisador do Laboratório de Estudos Teóricos e Analíticos sobre o Comportamento das Instituições (LETACI), Procurador Municipal e Advogado no Rio de Janeiro.
} 
estudo é a obra Mechanisms of Democracy de Adrian Vermeule. A partir deste marco de abordagem, pode-se perceber que o bom funcionamento de uma democracia deve combinar valores, instituições e seus desenhos de pequena escala, sem os quais o projeto constitucional perde em densidade normativa.

Palavras-Chave: Administração Pública; Controle Judicial; Desenhos Institucionais.

\begin{abstract}
Judicial control of the public administration is a subject on which the doctrine presents two specific cuts. The first one is of conceptual matrix. The second is of institutional matrix. In the first cut, doctrine often divides some phenomena into tied administrative acts and discretionary administrative acts. The related acts correspond to a mere operation of law enforcement in the face of the concrete situation. On the other hand, the discretionary acts would present greater margin of decision-making freedom for the public manager who took the decision. In this sense, there could only be substitution / annulment of the discretionary act by the judiciary in cases of reasonable violation of socially relevant assets and rights, while in the related acts control is total. It occurs that the inconsistency of the meaninglessness of an act to justify a responsible control over the administration opens space for institutional reflections. The objective of this paper is to review these two cuts, suggesting a second order approach to the problem of the legitimacy of judicial control of administrative actions. The theoretical reference for the study is the work Mechanisms of Democracy of Adrian Vermeule. From this framework of approach, one can see that the proper functioning of a democracy must combine values, and small scale institutional design, without which the constitutional project loses density.
\end{abstract}

KEYWORDS: Public Administration; Judicial Control; Institutional Designs. 


\section{SUMÁRIO:}

I. INTRODUÇÃO...............................................................................................213

II. O CONTROLE JUDICIAL DA ADMINISTRAÇÃO PÚBLICA E O SEU

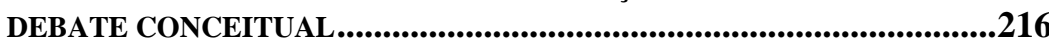

III. REFLEXÕES INSTITUCIONAIS SOBRE O CONTROLE JUDICIAL DA ADMINISTRAÇÃO PÚBLICA ..........................................................223

IV. UMA SUGESTÃO SOBRE O CONTROLE JUDICIAL DA ADMINISTRAÇÃO

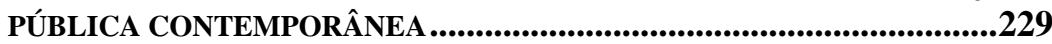

1. Estabelecendo a premissa.........................................................229

2. A contribuição teórica de segunda ordem de Adrian Vermeule .231

3. A aplicação de Adrian Vermeule na prática ........................234

V. CONCLUSÃo. .236

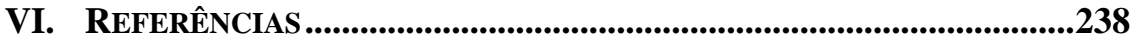

\section{TABLE OF CONTENTS:}

I. INTRODUCTION . .213

II. THE JUDICIAL REVIEW OF THE PUBLIC ADMINISTRATION AND ITS CONCEPTUAL DEBATE...................................................................216

III. INSTITUTIONAL REFLECTIONS ABOUT THE JUDICIAL REVIEW OF THE PUBLIC ADMINISTRATION

IV. A SUGESTION ABOUT THE JUDICIAL REVIEW OF THE CONTEMPORARY PUBLIC ADMINISTRATION

1. Stablishing the assumptions .......................................................229

2. The second order theoretical contribution of Adrian Vermeule

3. Applying Adrian Vermeule in practice................................234

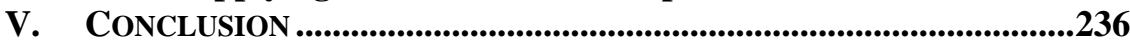

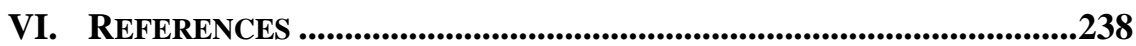




\section{INTRODUÇÃO}

A apreciação dos atos da administração pública pelo Poder Judiciário é uma forma, dentre outras, de controle do exercício do poder político. ${ }^{1}$ Mais especificamente, é através da previsão de censura jurídica sobre o comportamento da burocracia estatal que a sociedade contemporânea busca mitigar a prática de atos nocivos à vida das pessoas e ao funcionamento das instituições. Assim, a execução de programas legislativos ou a formatação de políticas públicas abrangentes são atitudes do poder executivo não isentas de questionamento legal. Acima de tudo, o motivo desse controle jurídico sobre a administração pública é evitar a violação de bens e direitos relevantes.

Por outro lado, a fiscalização judicial da administração não pode ser ilimitada. Isso porque um controle jurídico excessivo de um poder sobre outro pode gerar efeitos sistêmicos indesejáveis. ${ }^{2}$ A propósito, uma ilimitada fiscalização judicial desnaturaria, por completo, o sistema de separação de poderes, a partir da colonização do Executivo pelo Judiciário. Assim, quando o controle judicial não segue critérios bem definidos ou fica sujeito a parâmetros de atuação muito abstratos,

1 "Certamente, todos quantos fabricaram Constituições escritas consideraram tais instrumentos como a lei fundamental e predominante da nação e, consequentemente, a teoria de todo o governo, organizado por uma Constituição escrita, deve ser que é nula toda a resolução legislativa com ela incompatível. Assim, se uma lei está em oposição com a Constituição; se aplicadas ambas a um caso particular, o tribunal se vê na contingência de decidir a questão em conformidade da lei, desrespeitando a Constituição, ou consoante a Constituição, desrespeitando a lei; o tribunal deverá determinar qual destas regras em conflito regerá o caso. Essa é a verdadeira essência da função judicial." SOUTO, João Carlos. Marbury v Madison, 5 U.S. 137 (Cranch) 1803. In: João Carlos Souto. Suprema Corte dos Estados Unidos: Principais Decisões. $2^{\underline{a}}$ ed. São Paulo, SP: Atlas, 2015, p. 23.

2 "Neste contexto se alicerça a existência necessária de um espaço de reserva decisória a favor da Administração que se mostra insusceptível de ser 'devorado' ou 'invadido' primariamente pelos tribunais, sob pena de um modelo tecnocrático da função judicial, transformado o juiz em administrador do Estado-providência, subverter o sentido último da função judicial no quadro do Estado de Direito: uma hipervalorização do papel do juiz, negando a existência de uma reserva de Administração face ao poder judicial, perverterá o Estado de Direito num Estado judicial, conduzindo ao 'absolutismo jurisdicional'; regressar-se-á, por esta via, a uma fase de indiferenciação entre a função judicial e a função administrativa, agora sob a égide de um verdadeiro 'governo de juízes'." OTERO, Paulo. Legalidade e Administração Pública: o Sentido da Vinculação Administrativa à Juridicidade. Coimbra: Almedina, 2003, p. 289. 
problemas aparecem para a teoria constitucional. Para evitá-los, é preciso encontrar um ponto de equilíbrio. Visando achar tal ajuste, teóricos costumar dividir a análise do fenômeno em dois enfoques bem específicos: um conceitual e outro de perfil institucional.

O objetivo do presente artigo é repassar, sucintamente, essa bifurcação teórica que recai sobre as formulações acerca dos limites para o controle judicial das ações administrativas. E, a partir daí, apontar uma sugestão institucional de segunda ordem ${ }^{3}$ para o problema do controle judicial de uma administração pública complexa. Acredita-se que, com isso, seja possível oferecer uma contribuição para o tema, afastando-se as fórmulas teóricas que confiam demasiadamente em argumentos ideais ou na

3 "Raz irá sustentar que devemos distinguir razões de primeira e de segunda ordem, e que o conflito entre as primeiras é resolvido pelo peso relativo (ou força, o que dá no mesmo) das razões envolvidas, o que não se aplica ao conflito entre uma razão de primeira e outra, de segunda ordem. Vale anotar que, no uso comum da linguagem, fazemos referência a razões para explicar e guiar certas ações. Faz parte do cotidiano de todos fornecer razões para justificar atos que praticamos. Contudo, não é comum ouvir de um agente qualquer referência a razões de segunda ordem. E não é comum porque "razões de segunda ordem" simplesmente não fazem parte do discurso ordinário. Como bem observou Searle (1978, p. 81), se um termo estranho ao uso comum da linguagem é introduzido para fins de discussão de problemas filosóficos, ao menos duas perguntas devem ser formuladas (e respondidas): o que motiva o filósofo a introduzi-lo; e que outro termo se opõe a ele. Como será demonstrado, ambas as questões são formuladas e respondidas por Raz. (...) Se uma razão de primeira ordem é uma razão para praticar ou asbter-se de praticar uma certa ação, uma razão de segunda ordem será toda razão para agir ou abster-se de agir com base em outra ou outras razões (Raz, 2002, p. 39). Será chamada de razão excludente toda razão para não agir com base em certas razões (Raz, 2002, p. 183). Porque o conflito entre uma razão de primeira ordem e outra de segunda resolve-se de acordo com um princípio do raciocínio prático, segundo o qual uma razão excludente sempre prevalece, P2 precisa ser formulado: P2: não se deve agir de acordo com o balanceamento de razões se as razões que afetam o balanceamento são excluídas por uma razão excludente não derrotada (Raz, 2002, p. 38)." OLIVEIRA, Carlos Frederico Delage Junqueira de.

Identidade do Direito e Razões para a Ação: um estudo sobre as contribuições de Joseph Raz para a Teoria do Direito. 125 f. 2006. Dissertação (Mestrado em Direito), Programa de Pós-Graduação em Teoria do Estado e Direito Constitucional, Pontifícia Universidade Católica do Rio de Janeiro, Rio de Janeiro, 2006. Disponível em: $<$ https://www.maxwell.vrac.puc-

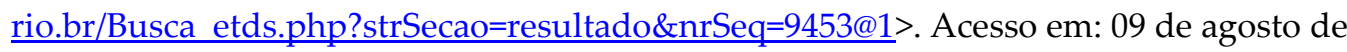
2017.

3 JOURNAL OF INSTITUTIONAL STUDIES 1 (2017) 
capacidade da doutrina de educar juízes. Assume-se como hipótese que os arranjos de macroescala, tais como supremacia constitucional, separação de poderes e democracia, são insuficientes para impedir uma atitude judicial ativista. ${ }^{4}$

Adotando uma metodologia argumentativa e prescritiva, o trabalho foi dividido em três partes. Na primeira, são abordadas as formulações teóricas conceituais sobre controle judicial da administração pública. São trabalhadas as categorias jurídicas do ato administrativo e de temas correlatos. Na segunda parte, o artigo investiga os parâmetros debatidos pela teoria institucional, bem como os seus problemas. A abordagem inclui considerações sobre capacidades e vieses dos agentes envolvidos no controle da máquina burocrática, incluindo alguns efeitos dinâmicos. Por fim, a última parte sugere um mecanismo decisional de segunda ordem que visa compatibilizar o controle da administração com uma limitação à atuação do Judiciário.

Pensar um mecanismo de segunda ordem justifica-se na medida em que o controle da administração não pode ser excessivamente casuístico, confiando no adequado manuseio de categorias jurídicas ideais pelas autoridades judiciárias. Tampouco o exercício do controle deve se guiar por argumentos imprecisos. Afinal, se não é viável formar consenso entre os intérpretes sobre o conteúdo da separação de poderes, muito menos este consenso é possível em critério tão aberto quanto a razoabilidade de uma ação estatal, por exemplo. A questão, assim, demanda aperfeiçoamento. Por isso, o artigo repassa, brevemente, as insuficiências teóricas existentes sobre a matéria, para só depois debater uma fórmula harmonizadora. Esta fórmula, de índole procedimental, será trabalhada à luz das contribuições teóricas de Adrian Vermeule. ${ }^{5}$

4 "Diversas objeções têm sido opostas, ao longo do tempo, à expansão do Poder Judiciário nos Estados constitucionais contemporâneos. Identificam-se aqui três delas. Tais críticas não infirmam a importância do papel desempenhado por juízes e tribunais nas democracias modernas, mas merecem consideração séria. $O$ modo de investidura dos juízes e membros de tribunais, sua formação específica e o tipo de discurso que utilizam são aspectos que exigem reflexão. Ninguém deseja o Judiciário como instância hegemônica e a interpretação constitucional não pode se transformar em usurpação da função legislativa. Aqui, como em quase tudo mais, impõe-se as virtudes da prudência e da moderação." BARROSO, Luís Roberto. O Novo Direito Constitucional Brasileiro: Contribuições para a Construção Teórica e Prática da Jurisdição Constitucional no Brasil. Belo Horizonte, MG: Fórum, 2012, p. 247.

${ }^{5}$ Cf. VERMEULE, Adrian. Mechanisms of Democracy: Institutional Design Writ Small. New York, NY: Oxford University Press, 2007. 


\section{O CONTROLE JUDICIAL DA ADMINISTRAÇÃO PÚBLICA E O SEU DEBATE CONCEITUAL}

Os pesquisadores de direito administrativo, no Brasil e alhures, normalmente subdividem o ato administrativo em ato vinculado e ato discricionário. ${ }^{6} \mathrm{~A}$ finalidade da referida subdivisão é múltipla. Não se trata apenas de uma construção didática para iniciantes, mas é também uma reflexão descritiva da realidade e prescritiva para o comportamento dos tribunais. Mais exatamente, essa caracterização tem aplicabilidade prescritiva na questão dos limites acerca da controlabilidade judicial da administração pública. ${ }^{7}$ Tal abordagem teórica pode ser considerada de matriz conceitual. Conforme ensina o professor Karl Larenz, a construção de conceitos assenta-se em reflexões sobre a descrição de fatos identificados na realidade da vida a partir de um determinado padrão que se repete e pode ser comprovado empiricamente. ${ }^{8}$

Em termos conceituais, o ato administrativo vinculado é compreendido como aquele que deve espelhar, na íntegra, a decisão tomada pelo legislador, ao passo que o ato discricionário é uma habilitação legislativa para o administrador agir com maior espaço de liberdade, à luz do caso concreto a ser examinado. ${ }^{9} \mathrm{O}$ primeiro conceito,

${ }^{6}$ MOREIRA NETO, Diogo de Figueiredo. Curso de Direito Administrativo: Parte

Introdutória, Parte Geral e Parte Especial. 16ª ed. Rio de Janeiro, RJ: Forense, 2014; e RIVERO, Jean. Direito Administrativo. Trad. Rogério Ehrhardt Soares. Coimbra: Almedina, 1981.

7 "O controlo do juiz, sendo um controle de legalidade, pára onde ela pára; não se estende, pois, ao poder discricionário, que depende da apreciação de oportunidade, estranha à missão do juiz." RIVERO, Jean. Direito Administrativo. Trad. Rogério Ehrhardt Soares. Coimbra: Almedina, 1981, p. 96.

8 LARENZ, Karl. Metodologia da Ciência do Direito. Trad. José Lamego. 3ª ed. Lisboa: Fundação Calouste Gulbenkian, 1997, p. 626.

9 "Ato vinculado, ou regrado, é aquele em que o agente tem competência para praticálo em estrita conformidade com as prescrições legislativas aplicáveis, manifestando a vontade da Administração na oportunidade e para os efeitos integralmente previstos na legislação, sem qualquer margem de escolha de atuação, seja de tempo, seja de conteúdo. (...) Ato discricionário, por outro lado, será aquele em que o agente tem competência para fazer escolhas, seja de oportunidade, de conveniência, do modo de sua realização, do alcance dos seus efeitos, de seu conteúdo jurídico, de suas condições acessórias, do momento de sua exeqüibilidade ou do destinatário ou destinatários da vontade da Administração, podendo ser apenas uma ou várias escolhas quanto a todos esses aspectos considerados, desde que rigorosamente contidas nos limites que lhe 
por ser espelho da lei, está sujeito ao controle abrangente do juiz, legítimo intérprete do direito. $\mathrm{O}$ segundo, por permitir a integração de uma vontade genuinamente administrativa, que se constitui a partir de parâmetros democráticos de legitimação, seria menos permeável à interferência judicial. Juízes devem deferência aos atos discricionários. ${ }^{10}$ Assim, a referida dicotomia expressa não apenas o que se passa na prática, mas prescreve a suscetibilidade de cada ato à revisão pelas instâncias judiciárias. Falar de ato vinculado e ato discricionário é falar, para os propósitos deste trabalho, em limites e possibilidades para a intervenção judicial sobre o comportamento da administração. ${ }^{11}$

Com o passar do tempo, a técnica legislativa vem entregando cada vez

foram abertos pela legislação." MOREIRA NETO, Diogo de Figueiredo. Curso de Direito Administrativo: Parte Introdutória, Parte Geral e Parte Especial. 16 ${ }^{\underline{a}}$ ed. Rio de Janeiro, RJ: Forense, 2014, p. 163. "Existe competência vinculada quando a norma jurídica impõe aos agentes aquela decisão que para eles decorre da reunião das condições que define; existe poder discricionário na medida em que ela lhes deixe uma certa liberdade de apreciação no exercício da sua competência." RIVERO, Jean. Direito Administrativo. Trad. Rogério Ehrhardt Soares. Coimbra: Almedina, 1981, p. 94. 10 “(...) Nas demais situações - quando não estejam em jogo os direitos fundamentais ou os procedimentos democráticos -, juízes e tribunais devem acatar as escolhas legítimas feitas pelo legislador, assim como ser deferentes com o exercício razoável de discricionariedade pelo administrador, abstendo-se de sobrepor-lhes razões ligadas à legitimidade democrática, como também em atenção às capacidades institucionais dos órgãos judiciários e sua impossibilidade de prever e administrar os efeitos sistêmicos das decisões proferidas em casos individuais. Os membros do Judiciário não devem presumir demais de si próprios - como ninguém deve, aliás, nessa vida -, supondo-se experts em todas as matérias." BARROSO, Luís Roberto. O Novo Direito Constitucional Brasileiro: Contribuições para a Construção Teórica e Prática da Jurisdição Constitucional no Brasil. Belo Horizonte, MG: Fórum, 2012, p. 251-252. ${ }^{11}$ Quando a máquina administrativa expede uma licença para construir, diz-se que o ato administrativo não pressupõe margem de apreciação subjetiva. Basta o decisor verificar a compatibilização do fato com a norma, de modo a expedir um ato administrativo denominado licença, que possui natureza jurídica vinculada. Por sua vez, se à administração incumbe proteger o meio ambiente, a programação para o atingimento deste fim específico diz-se discricionária, não sujeita a controle por parte do poder Judiciário. Age o Poder Público nesta hipótese mediante critérios de conveniência e oportunidade, ponderando uma série de custos e benefícios antes de agir. Enquanto o ato vinculado teria sua expedição sujeita a controle rigorosos, o ato discricionário seria menos controlável pelos juízes. Subjaz à discricionariedade a ideia de liberdade. 
mais liberdade à administração a partir do estabelecimento de fins a serem perseguidos pelo Estado. No mesmo sentido, os meios de atingimento desses fins são cada vez mais variados, sendo construídos através das chamadas políticas públicas. Conforme ensina Paulo Otero ${ }^{12}$, este fenômeno caracteriza o Estado administrativo, uma inevitabilidade histórica. O legislador não pode antecipar, prevenir ou controlar os novos problemas que espreitam as modernas sociedades desenvolvidas. Resta à função executiva integrar a juridicidade, mediante margem de atuação discricionária. ${ }^{13}$ Nada obstante, os teóricos também sustentam que os atos discricionários vão continuar carecendo de controle. ${ }^{14}$ Dessa inevitabilidade de controle, fundamental para um sistema de freios e contrapesos, decorrem então reforços conceituais para tentar ancorar o ato administrativo ao direito.

Exemplo ainda bastante atual sobre a tentativa de vinculação do ato discricionário ao direito é a dissecação dos atos administrativos em elementos constitutivos (competência, forma, finalidade, motivo e objeto). Dos cinco componentes do ato, três seriam suscetíveis a controle externo pela Justiça (competência, forma e finalidade). ${ }^{15}$ Igualmente, é

12 OTERO, Paulo. Legalidade e Administração Pública: o Sentido da Vinculação Administrativa à Juridicidade. Coimbra: Almedina, 2003, pp. 158-159.

13 “(...) o modelo de 'Estado legislativo-parlamentar' foi substituído pela centralidade do 'Estado-administrador', a lei revela-se insuficiente, obscura e ineficaz para fazer face às novas necessidades colectivas e o próprio conteúdo das normas jurídicas perde precisão, determinação e congruência, encontrando-se a legalidade eivada de interesses contraditórios e povoada de uma intrínseca conflitualidade normativa. Há aqui um movimento contraditório no desenvolvimento do Direito Administrativo: a legalidade tem um campo de operatividade vinculativa mais vasto mas, em contrapartida, o conteúdo da sua dimensão jurídico-positiva encontra-se debilitado e aponta, paradoxalmente, para um maior protagonismo ou 'activismo' dos órgãos administrativos na aplicação ou realização constitutiva do Direito." OTERO, Paulo. Legalidade e Administração Pública: o Sentido da Vinculação Administrativa à Juridicidade. Coimbra: Almedina, 2003, p. 292.

14 “Com efeito, qualquer acto está no mínimo submetido a duas condições impostas pelo direito; uma relativa à autoridade para o tomar, a outra relativa aos fins que deve perseguir e que não é, necessariamente, o interesse público; pelo menos nestes dois pontos a Administração está sempre vinculada." RIVERO, Jean. Direito Administrativo. Trad. Rogério Ehrhardt Soares. Coimbra: Almedina, 1981, p. 95. 15 "O ato administrativo discricionário, considerado analiticamente em seus cinco elementos, é o que apresenta três deles, necessariamente, vinculados (a competência, a finalidade e a forma) e um ou dois deles, discricionários (o motivo e o objeto)." 
possível mencionar as teorias posteriores sobre o desvio de poder, o excesso de poder e a vinculação administrativa aos motivos determinantes, agora como incremento do controle sobre o motivo e o objeto, inicialmente menos permeáveis a intervenções da Justiça. ${ }^{16}$ Tais construções visam compatibilizar o exercício da função administrativa dentro dos pressupostos do Estado de Direito, quais sejam: previsibilidade e respeito aos direitos fundamentais, tanto individuais quanto coletivos. ${ }^{17}$

Com o advento do constitucionalismo do pós-guerra, Gustavo Binenbojm $^{18}$ destaca que não se concebe mais uma atividade administrativa descolada da força normativa do direito constitucional. Além da lei, a administração encontra-se vinculada à Constituição, outrora sem relevância jurídica. De tal modo, o Poder Público agora não está mais restrito aos fins legais emanados do legislador. Seus atos estão circunscritos por parâmetros mais abrangentes, como as normas, os

MOREIRA NETO, Diogo de Figueiredo. Curso de Direito Administrativo: Parte Introdutória, Parte Geral e Parte Especial. 16ª ed. Rio de Janeiro, RJ: Forense, 2014, p. 163.

${ }^{16}$ BINENBOJM, Gustavo. Uma Teoria do Direito Administrativo: Direitos

Fundamentais, Democracia e Constitucionalização. Rio de Janeiro, RJ: Renovar, 2006, p. 197.

17 “Em consequencia, como assinala Maria Sylvia Zanella Di Pietro, a discricionariedade deixa de ser compreendida como um campo externo ao direito verdadeiro atavismo monárquico - para passar a ser vista como um poder jurídico. É dizer: um espaço decisório peculiar à Administração, não de escolhas puramente subjetivas, mas que se define pela prioridade das autoridades administrativas na fundamentação e legitimação dos atos e políticas públicas adotados, dentro de parâmetros jurídicos estabelecidos pela Constituição, pelas leis e por atos normativos editados pelas próprias entidades da Administração." BINENBOJM, Gustavo. Uma Teoria do Direito Administrativo: Direitos Fundamentais, Democracia e Constitucionalização. Rio de Janeiro, RJ: Renovar, 2006, p. 198.

18 "Assim, com a crise da lei formal, a Constituição - seu complexo sistema de princípios e regras - passa a ser o elo de unidade a costurar todo o arcabouço normativo que compõe o regime jurídico administrativo. A superação do paradigma da legalidade administrativa só pode ocorrer com a substituição da lei pela Constituição como cerne da vinculação administrativa à juridicidade." BINENBOJM, Gustavo. O Sentido da Vinculação Administrativa à Juridicidade no Direito Brasileiro. In: Alexandre dos Santos Aragão; Floriano de Azevedo Marques Neto. Direito Administrativo e seus Novos Paradigmas. (Orgs.). 2ª ed. Belo Horizonte, MG: Fórum, 2017, p. 180. 
princípios consagrados na Constituição e os fins nela determinados. Destaca-se que os conceitos de ato vinculado e ato discricionário, assim como seus elementos constitutivos e a própria teoria constitucional, passam a constituir um agregado teórico, servindo, cada qual a sua maneira, de ferramenta para o controle judicial mais reforçado da administração.

Apesar do esforço teórico de se juridicizar o ato administrativo discricionário, ainda não se chegou ao ponto de equiparar seu controle ao do ato vinculado. Muito ao contrário. A questão da discricionariedade administrativa permanece como uma necessidade não apenas teórica, mas também técnica. A administração pública, mesmo à luz da Constituição, continua responsável por concretizar os fins públicos e por traçar os meios adequados à consecução desses objetivos. Reforçando essa ideia, Marçal Justen Filho ${ }^{19}$ vai dizer que, mesmo na esteira da teoria constitucional contemporânea, repleta de princípios alçados ao status de normas vinculantes, somente situações excepcionais devem permitir ao juiz romper as fronteiras da discrição administrativa. O autor aduz que apenas decisões desarrazoadas, arbitrárias ou destituídas de qualquer aptidão para realizar a finalidade buscada podem ser substituídas por decisões judiciais.

À semelhança da doutrina brasileira, que teoriza sobre o controle da administração em grande parte de forma bipartida (ato vinculado $\mathrm{x}$ ato discricionário), nos Estados Unidos da América a doutrina Chevron também estabelece um critério binário de aferição judicial da conduta administrativa ao direito. No julgamento Cheoron USA Inc. versus Natural Resources Defense Council, Inc. (1984) ${ }^{20}$, a Suprema Corte americana estabeleceu que os tribunais do país devem apreciar se existe ou não

${ }^{19}$ JUSTEN FILHO, Marçal. Curso de Direito Administrativo. 9ª ed. São Paulo, SP:

Revista dos Tribunais, 2013, p. 261.

20 "Chevron defines a cluster of ideas about who is entrusted with interpreting ambiguous statutes and, less obviously, about what legal interpretation actually is. In its allocation of governmental authority and its production of outcomes in the real world, the importance of the case far exceeds that of the Supreme Court's more celebrated constitutional rulings on the subject of separation of powers in the 1980s, probably even if all of these are taken together. In an extraordinarily wide range of areas - including the environmental, welfare benefits, labor relations, civil rights, energy, food and drugs, banking, and many others - Chevron has altered the distribution of national powers among courts, Congress, and administrative agencies." SUNSTEIN, Cass. Law and Administration after Chevron. Columbia Law Review, Vol. 90, 8, 1990, p. 2.075. 
clareza na legislação administrativa. Caso a clareza esteja presente, a opção promovida pelo legislador deve ser concretizada. Via de consequência, o Judiciário pode substituir/ anular o ato administrativo por uma decisão judicial conformadora da lei. Entretanto, se a legislação apresentar ambiguidade, o papel do Judiciário é o de mero controlador da razoabilidade da escolha promovida pela autoridade pública, atuando apenas em casos extremos. ${ }^{21}$

Basicamente, a bipartição entre lei ambígua e lei clara promovida pelo caso Chevron revela que também nos EUA a atuação administrativa se divide em ato vinculado e ato discricionário. E, a depender do ato, um vai permitir controle, ao passo que o outro não. A lei clara seria a demonstração de que o legislador tem certeza sobre o caminho que deve ser percorrido, vinculando a administração à realização daquela conduta. Já a lei ambígua abre espaço para uma delegação de escolha do legislador à administração pública de acordo com as necessidades mais bem trabalhadas por quem lida com problemas na prática. Neste caso, a administração conta com um leque de escolhas, todas elas plausíveis, só cabendo ao juiz interferir se identificar extrema falta de razoabilidade na opção promovida pelas instâncias aplicadoras da lei.

Seja como for, tanto o exemplo brasileiro quanto a doutrina Chevron confiam em dois cenários ideais: no conceito de razoabilidade como algo verificável objetivamente no plano material durante o procedimento de controle judicial; e na capacidade de os juízes corretamente atenderem às

21 "With the advent of Mead and Walton, the Court has elaborated a fairly clear decision tree for adjudicating disputes over agency interpretations of statutes. First, the reviewing court should determine whether Congress intended to delegate law-like authority to the agency and whether the interpretation was promulgated in exercise of that authority. If so, the court must evaluate whether Congress has spoken clearly to the question at issue; if there is ambiguity or silence regarding the question, then any reasonable agency interpretation will be accepted. If there is no congressional intent to delegate law-like authority, then the agency is still entitled to deference under Skidmore if the context of its interpretation generates the 'power to persuade.' There are two points on this decision tree at which expertise plays a role: at 'Step Zero,' as one of several factors to consider if the agency's interpretation is not promulgated through a safe harbor; and as one factor in the Skidmore inquiry if the agency is not entitled to Chevron deference. Expertise also occasionally appears as an assumed motivation for Congress's delegation to the agency, although in this form it does no decisional work. Apart from these marginal applications of expertise, the Supreme Court's Chevron jurisprudence is rooted in congressional intent and the concomitant principle of separation of powers." THE HARVARD LAW REVIEW ASSOCIATION. The Two Faces of Chevron. Harvard Law Review, Vol. 120, 6, 2007, p. 1.562-1.584. 
expectativas de não assumir uma postura ativista, evitando substituir preferências de razoabilidade do gestor por suas preferências pessoais. É aqui que reside o problema. À medida que a sociedade se desenvolve, cada vez mais barreiras conceituais são insuficientes para impedir o governo dos juízes dissimulado de governo das leis (rule of Law). A criação de parâmetros conceituais pressupõe uma sociedade idealizada, que acredita na capacidade da literatura jurídica de exercer, por si só, uma força pedagógica eficaz em juízes de carne e osso.

Ao mesmo tempo em que o controle da administração pública corresponde a um imperativo civilizatório, a desmedida invasão das áreas de competência do Poder Executivo acaba por esvaziar o projeto constitucional de cooperação entre os poderes. É preciso respeitar a administração. Carlos Ari Sundfeld ${ }^{22}$ vai dizer que o direito limita e dirige a ação administrativa, mas não predetermina por inteiro os seus atos. Isso significa que nem todos os atos estão à mercê da opinião de juízes, por mais bem intencionados que os magistrados sejam. Não se trata de voltar a sustentar áreas de discricionariedade imperial, mas apenas de reconhecer que o mundo jurídico não tem - e não pode ter - todas as respostas para as necessidades sociais atuais. ${ }^{23} \mathrm{O}$ controle de razoabilidade, na prática, é insuficiente para evitar que juízes e tribunais excedam suas fronteiras de atuação, o que acaba por acarretar interferências contraproducentes em políticas regulatórias importantes, estranhas ao domínio intelectual da Justiça.

Insistir em enxergar a administração pública como um sujeito entre Caríbidis (legislador) e Cila (tribunais) não é mais um raciocínio adequado. ${ }^{24}$ A administração pública contemporânea absorve os impactos do progresso tecnológico, social e cultural, e precisa lidar com

${ }^{22}$ Cf. SUNDFELD, Carlos Ari. Direito Administrativo para Céticos. São Paulo, SP:

Malheiros, 2012.

${ }^{23}$ Cf. VERMEULE, Adrian. Law's Abnegation: From Law's Empire to the

Administrative State. Cambridge, MA: Harvard University Press, 2016.

${ }^{24}$ Cf. FERRY, Luc. A Sabedoria dos Mitos Gregos: Aprender a Viver II. Trad. Jorge

Bastos. Rio de Janeiro, RJ: Objetiva, 2012. Caríbdis e Cila são duas criaturas

aterrorizantes dos mares gregos, conhecidas por cruzar o caminho de navegantes, formando um pelotão de ataque inexpugnável. Caríbdis, um monstro feminino voraz, de dimensões olímpicas, formava um permanente e gigantesco redemoinho capaz de engolir embarcações inteiras sem piedade. Até era possível passar ao seu largo, de sorte a evitar um embate temerário. Mas, acaso o capitão do navio lograsse tamanho êxito, dificilmente conseguiria passar por Cila, um monstro marinho com seis cabeças de cão. 
as externalidades, sobretudo negativas, que eles promovem cotidianamente. Soluções expeditas e especializadas são uma necessidade que a sociedade demanda das autoridades administrativas subordinadas ao Poder Executivo e seus colaboradores, diretos e indiretos. Por conta disso, há uma cada vez maior transferência de competências do legislador para o gestor público, tencionado a promover resultados em vez de meramente aplicar uma lei pronta e acabada. Eduardo Jordão esclarece que a preocupação principal do direito administrativo mudou: de um foco sobre a lisura jurídica do agir administrativo, passa-se a aspectos de eficiência. ${ }^{25}$

Os aspectos de eficiência vão interferir na alocação de competências entre entidades públicas para decidir sobre questões socialmente relevantes. Não se trata mais de o administrador ser um puro conformador do direito, mas um gestor de cenários, em muitos casos econômicos, com elevado grau de incerteza, que nenhum juízo de razoabilidade tenciona medir. Por essa razão, o raio de ação do controle judicial sobre a discricionariedade administrativa, que deve existir, impõe a necessidade de se cogitar novas reflexões. Não mais uma questão jurídica - a separação de poderes - polariza com a interferência de juízes na prática administrativa. Ingressam na preocupação dos teóricos questões de expertise para enfrentar e prevenir ambientes nocivos, ou promover políticas públicas que sejam verdadeiramente democráticas. A insuficiência da matriz conceitual para enfrentar esse tema dá lugar à matriz institucional. ${ }^{26}$

\section{REFLEXÕES INSTITUCIONAIS SOBRE O CONTROLE JUDICIAL DA ADMINISTRAÇÃO PÚBLICA}

Análises institucionais ${ }^{27}$ comparativas entre judiciário e

${ }^{25}$ JORDÃO, Eduardo. Controle Judicial de uma Administração Pública Complexa: a experiência estrangeira na Adaptação da Intensidade do Controle. São Paulo, SP: Malheiros, 2016, p. 35.

${ }^{26}$ SOUZA, Rafael Bezerra de; BOLONHA, Carlos. Teorias Jurídicas Contemporâneas: uma análise crítica sob a perspectiva institucional. Direito, Estado e Sociedade, No. 43, 2013.

27 "Partindo-se de um marco teórico institucionalista, a legitimidade constitucional, estruturada sob parâmetros normativistas, parece ser insuficiente para compreender os acontecimentos e as circunstâncias presentes de natureza jurídico-política. Com o referencial teórico adotado, a ordem constitucional precisa ser concebida além de seu 
administração pública deixam de lado a pura hermenêutica de textos legais para passar a refletir sobre um fenômeno chamado alocação de poder decisório. Dessas abordagens institucionais, Eduardo Jordão ${ }^{28}$ explica que surgem relações tendenciais entre a natureza da decisão administrativa e o controle judicial que sobre ela deve recair. A abordagem não é mais se o legislador, em um determinado diploma legal, foi ou não claro na escolha de palavras ao editar uma lei. Importa à investigação debater as aptidões comparativas de juízes e administradores. Assim, se a decisão administrativa é juridicamente sensível, o controle judicial sobre ela deve ser não deferente. Se a decisão for política ou tecnicamente sensível, o controle a ser exercido pelos tribunais deve ser deferente. ${ }^{29}$

A separação entre decisão sensível do ponto de vista jurídico, técnico e político visa exemplificar três perfis decisórios normalmente identificados no âmbito da administração pública. Por exemplo, o corte de ponto em virtude do exercício do direito de greve por servidores públicos é uma decisão juridicamente sensível; por sua vez, a regulação de aromatizantes em cigarros de tabaco é uma decisão de perfil técnico; finalmente, a concessão de um serviço público à iniciativa privada ou sua exploração direta pelo Estado é uma decisão politicamente orientada. A

conteúdo normativo-constitucional, passando a ser integrada pela atividade das instituições que atuam neste plano. A legitimidade, desse modo, pode ser repensada no plano dos efeitos produzidos pela atividade institucional, oferecendo maior valor ao contexto resultante desta atuação, seja alterando a realidade fática de forma positiva, seja de forma negativa." BOLONHA, Carlos; RANGEL, Henrique; ALMEIDA, Maíra. A Proposta de uma Constituição Sistêmica. Revista Pensar (UNIFOR), Vol. 34, 1, 2014, p. 14. Disponível em $<$ http://www.periodicos.ufc.br/nomos/article/view/1185/1151>. Acesso em: 09 de agosto de 2017.

${ }^{28}$ Cf. JORDÃO, Eduardo. Controle Judicial de uma Administração Pública Complexa: a experiência estrangeira na Adaptação da Intensidade do Controle. São Paulo, SP: Malheiros, 2016.

29 “Como se vê, as relações tendenciais (...) fundamentam-se sobre análises institucionais comparativas. O objetivo é alocar poderes decisórios para as instituições mais adaptadas a tomar uma dada decisão, tendo em vista sua natureza. (...) o raciocínio institucionalista convida para uma análise mais pragmática, que leve em consideração as complexidades, incertezas e falibilidades que marcam o mundo real da aplicação do Direito." JORDÃO, Eduardo. Controle Judicial de uma Administração Pública Complexa: a experiência estrangeira na Adaptação da Intensidade do Controle. São Paulo, SP: Malheiros, 2016, p. 165. 
depender da natureza da conduta administrativa, o controle do judiciário vai ser legitimado de acordo com uma análise de compatibilização do desenho institucional da justiça com as características institucionais do órgão administrativo tomador da decisão.

O judiciário é um poder de controle especializado em questões jurídicas. Por isso, a tendência é que, ao se debruçar sobre um caso de aplicação e interpretação de leis e regulamentos, o controle sobre a decisão da administração seja não deferente. Isto é, sem necessidade de aceitar o parâmetro escolhido pelo gestor público. Estudos institucionais apontam que o desenho do judiciário é vocacionado para a proteção de direitos ou situações particularmente entrincheiradas pela sociedade. Os juízes ingressam na magistratura por concurso público de provas e títulos em direito, gozam de vitaliciedade e recebem remuneração compatível com a dignidade da função. Tais elementos permitem reunir pessoal experiente e preparado em assunto legislativo ${ }^{30}$, prudentemente distanciado da política partidária.

De fato, essas características estão sujeitas a falseamento diante de um caso específico, já que juízes são humanos e possuem vieses. A mesma lógica se aplica a qualquer outro agente com poder de decisão. No exemplo acima, decisões regulatórias podem ser tomadas a partir de um peso excessivo dado a determinado interesse, situação que só consegue neutralidade quando decidida por um terceiro imparcial. Por tal razão, fala-se em tendência, já que se admite que ela não seja observada diante de um caso específico. ${ }^{31}$ A mesma lógica se aplica às decisões políticas. A tendência nestas hipóteses é a abstenção do judiciário como regra, podendo não ser o caso se a solução em concreto recomendar o contrário. Seja como for, a relevância da formulação tendencial ganha força quando considerado o agregado dos casos.

Existem outras justificativas de cunho institucional para explicar um

30 "A interpretação legislativa é compreendida como a atividade jurídica por excelência. Assim, não haveria razão para que os tribunais evitassem intervir em interpretações da administração que julgassem equivocadas. A ideia subjacente é a de que a interpretação jurídica envolve uma competência particular. Não se trataria de mera leitura leiga dos dispositivos de lei. Envolveria - isto, sim - uma técnica específica, detida pelos sujeitos especializados no trato com o Direito." JORDÃO, Eduardo.

Controle Judicial de uma Administração Pública Complexa: a experiência estrangeira na Adaptação da Intensidade do Controle. São Paulo, SP: Malheiros, 2016, p.71.

31 Cf. ARGUELHES, Diego Werneck; LEAL, Fernando. O Argumento das "Capacidades Institucionais" entre a Banalidade, a Redundância e o Absurdo. Direito, Estado e Sociedade, No. 38, 2011. 
controle judicial tendencialmente não deferente em questões de direito. A administração pública está jungida ao princípio da legalidade. Ou seja, os servidores públicos devem, no exercício de suas funções, seguir parâmetros normativos formais. Sucede que a estrutura da administração não é composta apenas por profissionais do direito. Os cargos públicos são providos para diferentes áreas, para diferentes graus de escolaridade. Assim, a questão não significa que engenheiros ou economistas não saibam interpretar o direito. Significa que o direito possui especificidades que servidores de um órgão não jurídico pouco dominam, não apenas por ignorarem fenômenos jurídicos mais complexos, mas por apresentarem um viés setorial próprio das especializações funcionais.

De fato, nem toda decisão administrativa tem preponderância jurídica. Há os casos em que preponderam aspectos de seleção de meios para o atingimento de um determinado fim. ${ }^{32}$ Cuida tal fenômeno do aspecto político da administração. $\mathrm{O}$ controle sobre decisões políticas tenderá agora a ser deferente por outras razões institucionais. Isso não significa que juízes façam escolhas piores que agentes políticos, mas apenas aponta que juízes são menos adaptados a decidir politicamente que membros de escalão superior do Poder Executivo. Outrossim, decidir em tais hipóteses exige responsabilidade coletiva, que em uma democracia se obtém através de voto popular. Juízes não são eleitos. Já a cúpula do executivo é composta por pessoas eleitas ou integrantes de coalizões partidárias submetidas ao escrutínio eleitoral. A existência de uma base política faz da escolha da administração uma escolha coletivamente responsável. ${ }^{33}$

Outros argumentos podem ser utilizados para afastar juízes de escolhas políticas. O Judiciário é um poder inerte, caro e solene. Quem almeja uma decisão de um juiz postula providências com argumentação criteriosamente redigida, destacando pontos de vista parciais. Além de custas e taxas judiciárias elevadas, o ingresso em juízo exige a contratação de advogados com expertise em direito público. Apesar de mais aberto nos dias de hoje à participação de especialistas, os debates judiciais são informados por fórmulas de preclusão rigorosas, prevalecendo o estilo comunicacional dos bacharéis. A marcha processual tem rito específico, não podendo retornar no tempo à etapa já cumprida. Por fim, existe proibição de trazer fato novo e de debater, em instâncias superiores,

32 JORDÃO, Eduardo. Controle Judicial de uma Administração Pública Complexa: a experiência estrangeira na Adaptação da Intensidade do Controle. São Paulo, SP: Malheiros, 2016, p.81.

${ }^{33}$ Cf. VERMEULE, Adrian. Mechanisms of Democracy: Institutional Design Writ Small. New York, NY: Oxford University Press, 2007, p. 83. 
aspectos relacionados à apreciação de provas. Todos esses componentes desnaturam o judiciário como um fórum próprio para o debate de interesses políticos.

Neste campo específico, o controle judicial é deslocado para aspectos procedimentais, como o devido processo legal, o direito de participação e regras de publicidade. ${ }^{34}$

Outro campo de atuação deferente, sujeito a controle procedimental pelo judiciário, é a atividade administrativa de índole técnica. Além de não estarem habituados a tratar questões de natureza regulatória, aos tribunais falece capacidade institucional apropriada para operar com eficiência a distribuição de ônus e encargos num mercado em movimento. A falta de capacidade dos juízes em assunto de regulação é explicada pela prática cotidiana de magistrados. ${ }^{35}$ Eles só decidem fatos passados. A seu turno, a regulação pressupõe a utilização de métodos de análise de conjuntura e projeção de cenários, com margem de atuação muito mais prospectiva que retrospectiva. ${ }^{36}$ Outro fator que depõe contra os juízes é a necessidade de agilidade na escolha das ferramentas regulatórias. A liturgia judiciária é deveras morosa, sujeita a uma multiplicidade de impugnações e opiniões, não combinando com a velocidade de agentes investidores.

É fator relevante em matéria regulatória a alta especialização dos segmentos administrativos responsáveis por promover o planejamento público, fenômeno normalmente não encontrado no poder judiciário, restrito a temas de índole jurídica. A expertise da administração tende a limitar o controle judicial a aspectos puramente formais, sobretudo em termos de uso adequado dos protocolos exigidos para o setor regulado. Fora isso, o conteúdo da regulação é alvo de deferência, na medida em que falta a juízes capacidade técnica e os efeitos da intervenção judicial podem retardar a implementação de novas medidas ou elevar os custos sem que, para tanto, haja havido espaço para uma regular programação orçamentária, seja do poder público, seja do mercado.

$\mathrm{O}$ giro institucional promovido para enfrentar os problemas relacionados à separação de poderes e ao Estado de Direito contribuiu

${ }_{34}$ JORDÃO, Eduardo. Controle Judicial de uma Administração Pública Complexa: a experiência estrangeira na Adaptação da Intensidade do Controle. São Paulo, SP:

Malheiros, 2016, p. 109.

${ }^{35}$ Cf. SUNSTEIN, Cass; VERMEULE, Adrian. Interpretation and Institutions. Chicago

Public Law and Legal Theory Working Paper Series, No. 28, 2002.

${ }^{36}$ Cf. BEDNAR, Jenna; JONES-ROOY, Andrea; PAGE, Scott. Choosing a Future Based on the Past: Institutions, Behavior, and Path Dependence. European Journal of

Political Economy, Vol. 40, 2015. 
para a teoria do direito ampliar o olhar investigativo sobre o controle da administração pública. Esta abordagem muda a natureza da pesquisa acerca de como manter o administrador vinculado à lei: no lugar de exegeses sobre os textos normativos a serem aplicados, a fim de definir os contornos ou não do ato discricionário, tentou-se dividir o comportamento da administração em três atitudes preponderantes: aplicação de lei, escolha política e escolha técnica. Com base nisso, criouse uma presunção de legitimidade do ato por razões não hermenêuticas, mas de capacidades institucionais e efeitos dinâmicos. Mesmo assim, essa abordagem teórica apresenta alguns problemas.

É inegável que instituições importam para decisões presumidamente melhores. Mas além de ser necessário analisar empiricamente se a presunção se confirma, sob o risco de se argumentar sobre o vazio, também a divisão das decisões administrativas em jurídica, política e técnica simplifica demais algo que perfeitamente pode não ter sintonia com a prática. Sendo assim, pode-se dizer que a divisão da ação administrativa através de sua natureza padece de um problema insuperável: a despeito de toda argumentação que se exija do aplicador do direito, definir se uma decisão é política ou jurídica envolve muita subjetividade; e não é possível estabelecer com rigidez que toda decisão técnica, por exemplo, será objeto de apreciação deferente, de índole meramente procedimental. Pode haver casos em que, de maneira desejável, se inverta a tendência imaginada para o comportamento inicial do juiz controlador.

Eduardo Jordão sustenta que a identificação da natureza de uma decisão administrativa é um exercício subjetivo exercido por parte de quem se debruça sobre o problema real. ${ }^{37}$ Não há neutralidade neste procedimento, na medida em que decidir uma questão não é apenas uma obrigação do ponto de vista do direito, mas pode envolver outros interesses, como disputa de poder entre instituições concorrentes para afirmação de sua força no cenário político. Seja como for, mesmo que se aceite no agregado a subdivisão das ações administrativas e suas tendências de controle como um critério útil, problemas institucionais reais podem aparecer. Exemplo disso é a especialização exagerada do órgão regulador. Embora seja tecnicamente confiável, não está imune de ser parcial. É inegável que uma atividade regulatória, por ser técnica, está sujeita a viés e possui reduzido controle por parte das instâncias políticas. Em tais casos, o controle judicial é desejável, a fim de depurar as falhas

${ }^{37}$ Cf. JORDÃO, Eduardo. Controle Judicial de uma Administração Pública

Complexa: a experiência estrangeira na Adaptação da Intensidade do Controle. São Paulo, SP: Malheiros, 2016. 
do sistema institucional..$^{38}$

$\mathrm{Na}$ verdade, dividir o comportamento administrativo - e o correspondente espaço de atuação controladora do judiciário - em atos administrativos vinculados e atos administrativos discricionários como em atos jurídica, técnica e politicamente sensíveis representa puramente conceituar a multiplicidade de mecanismos que o poder público adota para exercer suas funções rotineiras. A diferença é que o primeiro caso adota a lei como critério definidor da natureza do ato, ao passo que o outro dá enfoque na substância preponderante da decisão em si da administração. Porém, ambos os critérios são conceituais e falhos, pois investem em categorizações que muitas vezes são falseadas pela empiria, não sendo suficientes para impor aos juízes e aos tribunais a necessária barreira de contenção para invasões devidas ou não da função administrativa.

\section{UMA SUGESTÃO SOBRE O CONTROLE JUDICIAL DA ADMINISTRAÇÃO PÚBLICA CONTEMPORÂNEA}

\section{Estabelecendo a premissa}

O controle judicial da administração pública, que não raro se desdobra em controle do ato administrativo ou em controle de políticas

38 "Podemos encontrar exemplos possíveis também nos debates sobre o controle judicial da atuação de agências reguladoras. Em trabalhos doutrinários, pode haver um tratamento assimétrico na comparação entre agências e tribunais. Isso ocorre quando, do lado dos juízes, enfatizam-se aspectos reais do exercício das atividades da maior parte desses profissionais - como o elevado número de processos, a formação generalista e inadequada para lidar com problemas complexos, a carência de suporte técnico para enfrentar problemas extrajurídicos. De outro, quando se compara o Judiciário com uma visão idealizada do que são agências reguladoras, ignorando problemas e riscos que, no mínimo em princípio, poderiam ocorrer na prática dentro do desenho institucional brasileiro, como, por exemplo, a possibilidade de captura. Só é possível reconhecer os limites de um controle externo sobre os agentes reguladores quando se incorpora a possibilidade de que esses agentes podem também falhar." LEAL, Fernando; ARGUELHES, Diego Werneck. Dois Problemas de Operacionalização do Argumento de Capacidades Institucionais. Revista Estudos Institucionais - REI, Vol. 2, 1, 2016, p. 204. Disponível em: $<$ https://www.estudosinstitucionais.com/REI/article/view/40>. Acesso em: 09 de agosto de 2017.

3 JOURNAL OF INSTITUTIONAL STUDIES 1 (2017) 
públicas ${ }^{39}$, apresenta alguns parâmetros consensuais entre os teóricos. $\mathrm{O}$ primeiro consenso consiste em reconhecer que o poder de efetivar na prática regras de direito e atos materiais de execução legislativa deve se submeter a um crivo revisional por parte de um terceiro imparcial especializado em matéria jurídica, objetivando preservar bens e valores socialmente relevantes. Por outro lado, é reconhecido também que nem todo ato emanado da administração comporta igual revisão em profundidade e extensão. Há casos, por exemplo, em que é recomendável a autocontenção judicial. Visa-se, com isso, preservar desde a separação de poderes até a especialização técnica de órgãos com competência executiva.

Nesse sentido, pode-se dizer que proteção adequada de direitos, controle do arbítrio, presunção de capacidade técnica e respeito à especialização temática de órgãos e agentes são todas razões de primeira ordem sobre a legitimidade do controle judicial da administração pública. $\mathrm{O}$ fato de existirem razões concorrentes não prejudica a natureza de primeira ordem dessas proposições. O conflito entre razões de primeira ordem é resolvido com base no peso relativo das razões em jogo. Todas convivem no mesmo plano e quando uma razão é aplicada a contraposta deixa de ser momentaneamente adotada. Assim, quando o tribunal presta deferência a uma política pública ambiental restritiva do direito de propriedade por razões técnicas, o direito de propriedade eventualmente prejudicado deixa de ser considerado como razão de decisão para o judiciário promover censura na ação administrativa. Quando uma regra de agência reguladora é anulada, o judiciário está afastando razões de índole técnica para aplicar razões de contenção do poder estatal à luz de valores como direitos individuais ou bens jurídicos mais relevantes que eventualmente venham a preponderar diante do caso.

Mas como definir o peso relativo das razões de primeira ordem? Que valores estariam por trás das escolhas?

Em abstrato, não é possível identificar quando o juiz irá falhar ou acertas nas razões aplicáveis, errando ou acertando no exercício de sua função jurisdicional. Com efeito, o juiz pode errar por desídia, ignorância, viés ou boa-fé. Também pode acertar mesmo que seu estado anímico não seja republicano. Não importa. As razões de primeira ordem sempre vão depender de um juiz para identificar, diante do caso concreto, a situação

${ }^{39}$ Cf. BARCELLOS, Ana Paula de. Neoconstitucionalismo, Direitos Fundamentais e Controle das Políticas Públicas. Revista de Direito Administrativo - RDA, No. 240, 2005. Disponível em:

<http://bibliotecadigital.fgv.br/ojs/index.php/rda/article/view/43620>. Acesso em: 09 agosto de 2017. 
controversa, presumindo que ele será, em qualquer cenário, apto a encontrar a melhor solução com base no arcabouço teórico colocado a sua disposição. Por outro lado, a premissa doravante trabalhada é: razões de primeira ordem não solucionam o impasse. Mas existe uma chance de se promover controle da administração pública com dose objetiva de responsabilidade: é através de razões de segunda ordem, ou seja, regras de decisão para juízes e tribunais aplicarem quando em causa uma ação administrativa.

\section{A contribuição teórica de segunda ordem de Adrian Vermeule}

Inicialmente, é preciso destacar que Adrian Vermeule argumenta que a reflexão acerca de dispositivos de pequena escala é capaz de contribuir com o aprimoramento de valores democráticos mais do que debater mecanismos de grande escala. ${ }^{40}$ São mecanismos de grande escala a separação de poderes, o federalismo e a república, entre outros. Ou seja, o direito constitucional pode cuidar de instituições de grande ou de pequena escala, sem ficar limitado em seu repertório de investigação. De qualquer forma, seria papel do direito pensar mecanismos menores, cujo impacto no ambiente institucional acabaria sendo, atualmente, muito mais significativo que debates abstratos sobre a estrutura e o funcionamento do Estado. Para o autor, democracias estabilizadas, como os EUA, os países da Europa e boa parte da América Latina, devem se preocupar mais em debater engrenagem que grandes estruturas.

Essas engrenagens de pequena escala estariam, segundo Vermeule, atreladas a quatro valores democráticos do constitucionalismo contemporâneo: imparcialidade, responsabilidade, transparência e deliberação. ${ }^{41}$ No tocante ao controle judicial da administração pública, a responsabilidade pela manutenção do desenho institucional de separação de poderes impõe refletir que espécies de mecanismos serviriam a coibir

40 "In this framework, the mechanisms of democracy are small-scale rules that structure the process by which laws are made, given the background institutions of the relevant constitutional democracy. So defined, mechanisms of democracy may be contrasted, on the one hand, with large-scale institutional arrangements, as above; they may also be contrasted with constitutional or legal rules that directly police the outcomes of democratic institutions, such as rules protecting individual rights and liberties." VERMEULE, Adrian. Mechanisms of Democracy: Institutional Design Writ Small. New York, NY: Oxford University Press, 2007, p. 4.

${ }^{41}$ VERMEULE, Adrian. Mechanisms of Democracy: Institutional Design Writ Small. New York, NY: Oxford University Press, 2007, p. 4. 
posturas judiciais inapropriadas. Para teóricos da democracia, responsabilidade denota o compromisso com a preservação das funções precípuas dos poderes regularmente constituídos. Assim, argumentos de primeira ordem idealizam as responsabilidades quanto aos precisos limites de atuação dos três poderes. Para aperfeiçoar esse ponto, faz-se mister pensar a otimização de responsabilidades através de um desenho institucional específico.

Pensar em desenhos institucionais de pequena escala para o controle judicial da administração pública coincide com as reflexões do professor Adrian Vermeule sobre novas fórmulas de promoção da democracia. Afinal, a democracia também pode ser um dispositivo para regular conflitos políticos. Ora, quando um juiz derruba uma política pública, claramente existe aí um conflito político, caracterizado não por divergências partidárias, mas pela disputa entre dois órgãos distintos e independentes, inclusive em termos de chevron democrático, sobre o que é melhor ou não para o universo da população. As instituições de larga escala, de fato, contribuem para a estabilidade dos argumentos, mas nem por isso são úteis em termos de solução de controvérsias.

Um juiz que derruba uma ação administrativa, por ausência de razoabilidade, está transformando o país em um Estado não democrático? Ou um juiz que abdica de controlar a ação administrativa está sendo leniente para a extinção da rule of Law? Para problemas concretos, os argumentos de larga escala apresentam limitações. Portanto, ajustes institucionais mediante pequenas reformas podem promover ideais democráticos de modo muito mais eficiente que reformar toda uma ordem constitucional. No campo do controle da administração pública, a saída seria cogitar a respeito de regras judiciais de votação em órgãos colegiados, capazes de regular os resultados da interação entre justiça e executivo.

Por isso, mecanismos democráticos podem promover um melhor resultado à luz dos conflitos concretos. Os arranjos institucionais de segunda ordem são mais bem adaptados para alcançar metas substantivas através de bons efeitos colaterais que arranjos de primeira ordem. O melhor de tudo: a baixo custo de transação. Para os objetivos do presente artigo, que é compatibilizar controle da administração dentro de parâmetros bem definidos, somente a internalização de regras de segunda ordem nas decisões dos tribunais pode criar uma proteção prima facie dos atos administrativos, sem, todavia, impedir que eles sejam adequadamente controlados. A questão leva a sério a presunção de validade dos atos estatais a partir de um quórum mínimo de aprovação.

Cuidando de órgãos colegiados de feição legislativa, Vermeule teoriza sobre regras de votação para o alcance de maiorias consistentes em um 
ambiente de inerente divergência ideológica. ${ }^{42}$ Como no direito brasileiro os tribunais apresentam composição colegiada, pluralista e competências originárias para julgar atos genéricos e abstratos, entende-se neste trabalho que a formulação desenvolvida pelo referido professor pode ser perfeitamente utilizada. De tal forma, a natureza do órgão colegiado não importa, bastando que ele seja uma instituição que tome decisões com base em alguma regra de maioria numérica. $\mathrm{O}$ que deve ser considerado na contribuição teórica de Vermeule é o respeito a uma forma de decisão interna que seja capaz de proteger o status quo prima facie.

As regras de votação majoritárias podem contribuir para otimizar a responsabilidade de tribunais toda vez que em causa assuntos regulatórios ou decisões administrativas complexas. Isso porque a deferência exigida em face da atividade administrativa não pode estar ao livre alvedrio do julgador, ou do perfil que compõe este ou aquele colegiado, mas constituir uma regra procedimental de tomada de decisão, independentemente do meritum causae e do lado subjetivo do decisor. O desenho de regras de votação é um típico mecanismo democrático cuja característica de pequena escala tem o condão de contribuir no atingimento de relevantes efeitos em termos de harmonização da separação de poderes e da sujeição do administrador a parâmetros de razoabilidade.

É preciso destacar que existem várias regras de votação majoritária e que não são todas que Vermeule considera aptas para o desiderato democrático. ${ }^{43}$ Por exemplo: regra de votação majoritária em que se mede o resultado alcançado pelo número de votantes presentes não é uma boa solução. Segundo o autor, esse tipo de procedimento permite que haja manipulação durante o escrutínio, dado o alto peso que a sistemática proporciona à abstenção no resultado final. Grupos sem opinião formada podem, a depender da conjuntura, negociar seus votos e suas presenças para interferir na balança. Isso permite que em debates sociais relevantes o resultado alcançado não seja fruto de um amadurecimento intelectual, mas sim da capacidade de o interessado no tema negociar com eficiência, nem sempre republicana, a posição preferencial de grupos fisiológicos.

A regra de votação sustentada por Vermeule é a regra de maioria absoluta. Esta prova ser, na prática, democraticamente superior à regra de maioria simples. Afinal, ela impede maiorias ocasionais formadas sem o consenso necessário dos votantes. Além disso, condutas ardilosas da

42 VERMEULE, Adrian. Mechanisms of Democracy: Institutional Design Writ Small. New York, NY: Oxford University Press, 2007, p. 115-.142.

43 VERMEULE, Adrian. Mechanisms of Democracy: Institutional Design Writ Small. New York, NY: Oxford University Press, 2007, p. 99-100. 
minoria são afastadas. A metodologia de funcionamento da regra de maioria absoluta é a seguinte: o quórum considerado para apurar o resultado final de uma deliberação colegiada leva em consideração a totalidade dos votantes; o objeto da deliberação precisa alcançar a maioria mais um voto dos integrantes do órgão, e não dos membros presentes, após apurado o quórum de instauração da sessão. Na regra de maioria absoluta, a proteção do status quo milita em favor da deferência judicial em face das decisões administrativas. Aos argumentos tendenciais de primeira ordem pode-se agregar a regra de segunda ordem, para impedir interferências que não gozem de deliberação e bloco de opiniões consistentes.

\section{A aplicação de Adrian Vermeule na prática}

É preciso destacar que o direito brasileiro não é indiferente a regras de procedimento judicial por maioria absoluta, voltadas à preservação de certas presunções de legitimidade. Em sede de controle repressivo de constitucionalidade, tanto pela via da ação direta quanto pela via da exceção, o ordenamento nacional estabelece regra de decisão de segunda ordem. ${ }^{44}$ No caso do controle de constitucionalidade das leis pela via da ação direta, um ato normativo primário emanado do legislativo só é derrubado por vício formal ou material de constitucionalidade se o resultado da votação alcançar a maioria absoluta dos componentes do tribunal. Por sua vez, o controle difuso de constitucionalidade exige, sem sede recursal, a cláusula de reserva de plenário. ${ }^{45} \mathrm{O}$ intuito não é impedir erros, mas amarrar todo o tribunal em torno de um resultado, sem que internamente o tribunal possa decidir com base em manipulação de quórum.

Sem dúvida, a existência desta regra tem por objetivo preservar a presunção de constitucionalidade das leis, levando em consideração

${ }^{44}$ Lei no 9.868/1999: “Art. 23. Efetuado o julgamento, proclamar-se-á a constitucionalidade ou a inconstitucionalidade da disposição ou da norma impugnada se num ou noutro sentido se tiverem manifestado pelo menos seis Ministros, quer se trate de ação direta de inconstitucionalidade ou de ação declaratória de constitucionalidade."

${ }^{45}$ Constituição da República Federativa do Brasil: "Art. 97. Somente pelo voto da maioria absoluta de seus membros ou dos membros do respectivo órgão especial poderão os tribunais declarar a inconstitucionalidade de lei ou ato normativo do Poder Público." 
aspectos institucionais. $\mathrm{O}$ parlamento tem responsabilidade diante da população que o elegeu. Sendo assim, deve governar orientado pelas aspirações populares. Contudo, há limites para essas aspirações, como o direito a existência das minorias. Cabe ao judiciário, pois, guardar esses direitos. Entretanto, não cabe ao judiciário definir políticas públicas de acordo com critérios de conveniência e oportunidade. Então os tribunais precisam guardar deferência ao produto parlamentar, sempre que possível. De nada adiantaria conclamar pela deferência judicial ao parlamento sem uma regra de votação que fizesse valer na prática um princípio de deferência institucional que vinculasse toda a corte.

Ora, se assim é para o controle da prática legislativa, nada impediria que a mesma lógica fosse aplicada em sede de controle judicial da administração pública de forma mais categórica, mormente em sede de políticas regulatórias, situação em que regulamentos são expedidos com elevado grau de abrangência e criatividade normativa. Com efeito, a jurisprudência do Supremo Tribunal Federal reconhece a possibilidade de julgamento de ações diretas de inconstitucionalidade contra ato administrativo primário, a despeito de não ser uma lei em sentido formal, que vier a inovar a ordem jurídica mediante generalidade e abstração. ${ }^{46}$ Mas a questão do controle de atos administrativos mediante quórum de deliberação não tem eco atualmente.

Conforme mencionado no primeiro tópico do artigo, a doutrina divide os atos administrativos em vinculados e discricionários. A divisão não é inútil, muito pelo contrário. Tem muita utilidade prática, embora não resolva na totalidade o problema do controle judicial responsável sobre a administração pública. Assim, pode-se cogitar de um mecanismo de segunda ordem para o controle de ato administrativo discricionário nos tribunais. Isso se daria mediante aplicação da cláusula de reserva de plenário, ao passo que o controle do ato vinculado poderia ser controlado sem essa exigência formal de quórum.

$\mathrm{O}$ ato discricionário, quando sofre censura judicial, normalmente o sofre mediante argumentação principiológica reconduzida ao caput do artigo 37 da Constituição da República Federativa do Brasil. Portanto, moralidade, eficiência, impessoalidade e publicidade são argumentos constitucionais, que justificariam uma regra de segunda ordem para a declaração de nulidade de um ato dessa natureza. A cláusula de reserva de plenário existente hoje para os atos normativos legislativos pode ser aplicada aos atos discricionários, sobretudo os provenientes das agências. A legalidade, a despeito de ser um argumento também constitucional, quando violada já enseja um controle de vinculação do ato, algo que não

${ }^{46}$ STF, ADI 2.950-AgR, Min. Red. Eros Grau, Julgamento em 06/10/04.

3 JOURNAL OF INSTITUTIONAL STUDIES 1 (2017) 
demanda quórum reforçado pelos tribunais. Afinal, a característica do ato puramente ilegal não enseja juízo acirrado de valor sobre preferências políticas, razão pela qual o judiciário não precisaria aqui de um consenso reforçado para decidir.

A exemplificação promovida é de lege ferenda, mas tem o propósito de assimilar a proposta de combinar não apenas bons argumentos de primeira ordem, mas também mecanismos de segunda ordem para se desenhar instituições mais responsivas.

Sem dúvida, a questão do controle judicial sobre a administração pública é em si turbulenta e demanda aprofundamento acerca do desenho adequado para sua realização. Compatibilizar estado de direito e responsabilidade por decisões que cada poder constitucional toma com base em suas competências é um desafio. Portanto, o encaminhamento que se faz no presente trabalho é quanto a necessidade de se integrar razões de primeira ordem com razões de segunda ordem, incorporando ao debate constitucional contemporâneo mecanismos de pequena escala às grandes controvérsias da teoria constitucional. Com essa fusão, podese produzir um equilíbrio entre poderes que interagem e, não raro, disputam espaço entre si, afastando argumentos conceituais muitas vezes retóricos sobre o controle que deve ser promovido no caso concreto.

\section{CONCLUSÃo}

Pretendeu-se debater, com concisão, alguns aspectos relacionados ao controle judicial da administração pública. Viu-se que existem dois enfoques sobre o tema: um de natureza conceitual e outro de natureza institucional. $\mathrm{O}$ enfoque conceitual visa caracterizar os atos da administração, promovendo sobre ele divisões que permitiriam identificar em que casos poderiam os tribunais anular/ substituir a escolha administrativa por uma escolha da justiça. A questão, em tais hipóteses, dependeria de uma exegese legal. Seria através da hermenêutica de textos legais que se extrairia a possibilidade ou não de maior ingerência dos tribunais sobre as decisões administrativas.

A seu turno, o enfoque institucional divide o tema de acordo com o perfil das instituições em causa, segregando quais hipóteses poderiam ser mais ou menos controladas pelo judiciário. $\mathrm{O}$ destaque deste perfil de investigação não é para a redação dos textos legais, mas sim para a característica principal das instituições democráticas. Os tribunais são órgãos técnicos, seus integrantes não são eleitos e chegam ao poder mediante prova de conhecimento em direito. Juízes estariam então mais bem aparelhados para controlar decisões juridicamente delicadas do 
poder público, a fim de salvaguardar bens e direitos que independem do governo de ocasião. Por outro lado, assuntos técnicos de outras esferas e matérias políticas deveriam ser mantidos por tribunais, ante a incomum habilidade de magistrados para operar em campos fora do direito.

Ocorre que também argumentos institucionais falham, sobretudo porque apostam em dois tipos de formulação: a primeira formulação consistente em pensar argumentos idealizados. Como consequência desta idealização, as teorias confiam que juízes, diante do caso concreto, decidirão de acordo com os modelos em vez de decidir conforme suas próprias preferências. Os dois problemas se conjugam: ao idealizar as razões de decidir, idealiza-se o decisor. A única chance para minorar esses dois problemas é desenvolver investigações de segunda ordem, que sejam capazes não de excluir as razões de primeira, mas de complementálas através de mecanismos institucionais internos, tanto em parlamentos quanto em tribunais.

Como marco teórico do artigo, utilizou-se o livro Mechanisms of Democracy de Adrian Vermeule. Nele, o professor de Harvard trata de regras de maioria absoluta de votação como razão de segunda ordem para proteger o status quo de manipulações de agentes decisores. $\mathrm{O}$ modelo tem aderência com o debate do controle judicial da administração pública, na medida em que a presunção de legitimidade dos atos administrativos não serve de nada se não for acompanhada de uma regra de votação que só a derrube por maioria absoluta dos julgadores presentes, atrelando todo o tribunal à responsabilidade pelas consequências do controle não deferente. No direito brasileiro, modelo similar é adotado no julgamento de controle de constitucionalidade das leis. A regra poderia ser estendida para apreciação de atos administrativos e políticas públicas, evitando que o poder judiciário derrubasse medidas de outro poder senão quando legitimada por um quórum de aprovação consistente.

A regra de votos por maioria absoluta não garante a correção da decisão do tribunal. Entretanto, assegura uma deliberação mais prolongada sobre a matéria posta em votação, sem falar na vinculação institucional do tribunal com os valores democráticos. Integrantes dos órgãos políticos não costumar adotar, no agregado de suas ações, uma postura autodestrutiva. Com isso, juízes podem convencer seus pares de que o ponto de vista que adotam são os mais seguros para a democracia. Ademais, ao demonstrar zelo e cuidado para com a atividade administrativa, o Judiciário evita efeitos sistêmicos decorrentes da superação de estudos, prognoses e avaliações técnicas. É preciso destacar que discordância ideológica de juízes tem custos. Portanto, a substituição/ anulação de um ato administrativo, sobretudo discricionário, deve ser pautado por parâmetros que operem, concretamente, no microcosmo das 
instituições controladoras.

\section{REFERÊNCIAS}

ARGUELHES, Diego Werneck; LEAL, Fernando. O Argumento das "Capacidades Institucionais" entre a Banalidade, a Redundância e o Absurdo. Direito, Estado e Sociedade, No. 38, 2011.

BARCELLOS, Ana Paula de. Neoconstitucionalismo, Direitos Fundamentais e Controle das Políticas Públicas. Revista de Direito Administrativo - RDA, No. 240, 2005. Disponível em: $<$ http://bibliotecadigital.fgv.br/ojs/index.php/rda/article/view/43620>. Acesso em: 09 agosto de 2017.

BARROSO, Luís Roberto. O Novo Direito Constitucional Brasileiro: Contribuições para a Construção Teórica e Prática da Jurisdição Constitucional no Brasil. Belo Horizonte, MG: Fórum, 2012.

BEDNAR, Jenna; JONES-ROOY, Andrea; PAGE, Scott. Choosing a Future Based on the Past: Institutions, Behavior, and Path Dependence. European Journal of Political Economy, Vol. 40, 2015.

BINENBOJM, Gustavo. O Sentido da Vinculação Administrativa à Juridicidade no Direito Brasileiro. In: Alexandre dos Santos Aragão; Floriano de Azevedo Marques Neto. Direito Administrativo e seus Novos Paradigmas. (Orgs.). 2ª ed. Belo Horizonte, MG: Fórum, 2017.

\section{. Uma Teoria do Direito Administrativo: Direitos}

Fundamentais, Democracia e Constitucionalização. Rio de Janeiro, RJ:

Renovar, 2006. 
BOLONHA, Carlos; RANGEL, Henrique; ALMEIDA, Maíra. A Proposta de uma Constituição Sistêmica. Revista Pensar (UNIFOR), Vol. 34, 1, 2014. Disponível em $<$ http://www.periodicos.ufc.br/nomos/article/view/1185/1151>. Acesso em: 09 de agosto de 2017.

FERRY, Luc. A Sabedoria dos Mitos Gregos: Aprender a Viver II. Trad. Jorge Bastos. Rio de Janeiro, RJ: Objetiva, 2012.

JORDÃO, Eduardo. Controle Judicial de uma Administração Pública Complexa: a experiência estrangeira na Adaptação da Intensidade do Controle. São Paulo, SP: Malheiros, 2016.

JUSTEN FILHO, Marçal. Curso de Direito Administrativo. 9ª ed. São Paulo, SP: Revista dos Tribunais, 2013.

LARENZ, Karl. Metodologia da Ciência do Direito. Trad. José Lamego. 3ª ed. Lisboa: Fundação Calouste Gulbenkian, 1997.

LEAL, Fernando; ARGUELHES, Diego Werneck. Dois Problemas de Operacionalização do Argumento de Capacidades Institucionais. Revista Estudos Institucionais - REI, Vol. 2, 1, 2016, p. 204. Disponível em: $\langle$ https://www.estudosinstitucionais.com/REI/article/view/40>. Acesso em: 09 de agosto de 2017.

MOREIRA NETO, Diogo de Figueiredo. Curso de Direito Administrativo: Parte Introdutória, Parte Geral e Parte Especial. 16 ed. Rio de Janeiro, RJ: Forense, 2014.

OLIVEIRA, Carlos Frederico Delage Junqueira de. Identidade do Direito e Razões para a Ação: um estudo sobre as contribuições de Joseph Raz para a Teoria do Direito. 125 f. 2006. Dissertação (Mestrado em Direito), Programa de Pós-Graduação em Teoria Geral do Estado e Direito Constitucional, Pontifícia Universidade Católica do Rio de 
Janeiro, Rio de Janeiro, 2006. Disponível

em: $<$ https://www.maxwell.vrac.puc-

rio.br/Busca etds.php?strSecao=resultado\&nrSeq=9453@1>. Acesso em:

09 de agosto de 2017.

OTERO, Paulo. Legalidade e Administração Pública: o Sentido da

Vinculação Administrativa à Juridicidade. Coimbra: Almedina, 2003.

RIVERO, Jean. Direito Administrativo. Trad. Rogério Ehrhardt Soares. Coimbra: Almedina, 1981.

SOUTO, João Carlos. Marbury v Madison, 5 U.S. 137 (Cranch) - 1803. In: João Carlos Souto. Suprema Corte dos Estados Unidos: Principais Decisões. $2^{\underline{a}}$ ed. São Paulo, SP: Atlas, 2015.

SOUZA, Rafael Bezerra de; BOLONHA, Carlos. Teorias Jurídicas Contemporâneas: uma análise crítica sob a perspectiva institucional. Direito, Estado e Sociedade, No. 43, 2013..

SUNDFELD, Carlos Ari. Direito Administrativo para Céticos. São Paulo, SP: Malheiros, 2012.

SUNSTEIN, Cass. Law and Administration after Chevron. Columbia Law Review, Vol. 90, 8, 1990.

SUNSTEIN, Cass; VERMEULE, Adrian. Interpretation and Institutions. Chicago Public Law and Legal Theory Working Paper Series, No. 28, 2002.

THE HARVARD LAW REVIEW ASSOCIATION. The Two Faces of Cheoron. Harvard Law Review, Vol. 120, 6, 2007.

VERMEULE, Adrian. Law's Abnegation: From Law's Empire to the Administrative State. Cambridge, MA: Harvard University Press, 2016. 
. Mechanisms of Democracy: Institutional Design Writ Small.

New York, NY: Oxford University Press, 2007.

Algumas Reflexões sobre o Controle Judicial da Administração Pública Contemporânea Some Reflections about the Judicial Review of the Contemporary Public Administration Submetido em: 2017-06-31

Aceito em: 2017-07-29 